\title{
Imaging an Underwater Basin and its Resonance Modes using Optical Fiber Distributed Acoustic Sensing
}

\author{
Itzhak Lior ${ }^{1,2}$, E. Diego Mercerat ${ }^{3}$, Diane Rivet ${ }^{2}$, Anthony Sladen ${ }^{2}$ and Jean-Paul \\ Ampuero ${ }^{2}$ \\ ${ }^{1}$ Institute of Earth Sciences, The Hebrew University, Jerusalem, Israel \\ ${ }^{2}$ Universite Cote d'Azur, CNRS, Observatoire de la cote d'Azur, IRD, Geoazur \\ ${ }^{3}$ CEREMA, equipe MouvGS, Sophia Antipolis, Valbonne, France \\ Corresponding author: Itzhak Lior (itzhak.lior@mail.huji.ac.il)
}

\section{Key Points:}

Ambient noise observations using an optical fiber in an underwater basin reveal highresolution seismic response and resonance effects

Shear-wave velocity is imaged via Scholte-wave dispersion and seismic response is revealed via power spectral density and auto-correlation

The inferred velocity model is supported by 2D simulations of wave propagation

This manuscript has been submitted for publication in Geophysical Research Letters, and is not peer-reviewed yet. Subsequent versions of this manuscript may have different content. 


\begin{abstract}
Distributed acoustic sensing is an ideal tool for ambient noise tomography owing to the dense spatial measurements and the ability to continuously record in harsh environments, such as underwater. We demonstrate the ability to image a complex underwater basin using ambient noise recorded on a fiber deployed offshore Greece. A two-dimensional shear-wave velocity model was derived by analyzing Scholte-wave dispersion. In addition, extremely detailed frequency-dependent resonance and wave propagation characteristics were revealed by computing power spectral densities (PSD) and auto-correlations (AC), respectively. These observations provide crucial information on lateral and vertical wave propagation, and were used to further constrain the velocity model. The analysis reveals significant lateral variations across the short $2.5 \mathrm{~km}$ long fiber segment, including basin edge effects and scattered waves. Waveform simulations further support the obtained model. Our results demonstrate the advantages of incorporating PSD and AC observations into ambient noise-based imaging.
\end{abstract}

\title{
Plain language summary
}

Distributed acoustic sensing is a new technique that enables continuous seismic measurements every few meters along optical fibers. We use seismic noise recorded by an underwater fiber deployed offshore Greece to demonstrate the ability to resolve the subsurface structure of a complex underwater basin. The two-dimensional shear-wave velocity model beneath the fiber was estimated by analyzing seismic ambient noise propagation characteristics. In addition, the resonance of waves inside the basin was analyzed by computing noise power spectral densities (PSD) and auto-correlations (AC). The former reveals the basin's resonance modes along the fiber and the latter reveals continuous wave propagation characteristics, both reveal the complex interactions between vertical and lateral wave propagation within the basin. The $2 \mathrm{D}$ velocity model was further constrained by the PSD and AC images. Waveform simulations support the revised model. Our results demonstrate the advantages of incorporating PSD and AC observations into ambient noise-based subsurface imaging.

\section{Introduction}

In recent decades, ambient noise tomography has become a common practice in seismology to accurately image subsurface velocity structures (e.g., Shapiro \& Campillo, 2004). This objective is typically achieved by extracting Green's functions between pairs of receivers using cross-correlations $(\mathrm{CC})$ of continuous ambient noise recordings (e.g., Foti et al., 2018). These Green's functions, calculated under the assumption of diffuse random wavefields, are then used to resolve the subsurface velocity structure by extracting and analyzing the dispersive properties of surface waves (Park et al., 1999). This method has been successfully applied at global (Nishida et al., 2009) and regional scales (e.g., Guerin et al., 2020; Lin et al. 2008; Mordret et al. 2014).

The scale of ambient noise derived velocity models is currently limited by the geometry of available seismic networks. Seismic sensors are typically deployed at interstation distances of tens to hundreds of kilometers, limiting the spatial resolution of derived velocity models. In addition, underwater seismic recordings are scarce, because of the high cost of deploying and maintaining arrays of ocean-bottom seismometers. Owing to the vast underwater observational gap, only a few studies imaged underwater velocity structures (Guerin et al., 2020; Hable et al., 2019; Mordret et al., 2014; Wolf et al., 2021; Yao et al., 
2011). An ideal solution to these two hindrances is the use of distributed acoustic sensing (DAS) on seafloor fiber-optic cables.

The novel technique of DAS enables the transformation of standard optical fibers into dense seismic arrays, continuously recording deformation time-series every few meters across tens of kilometers of fibers. Such measurements have already been utilized for ambient noise tomography both on-land (e.g., Ajo-Franklin et al., 2019; Dou et al., 2017; Yuan et al., 2020) and underwater (Cheng et al., 2021; Spica et al., 2020; Tonegawa et al., 2021; Williams et al., 2021). This high-resolution technique is especially advantageous for ocean-bottom applications since the interrogator is only connected to the on-land end of the fiber, circumventing costly underwater operations.

Unlike previous DAS ocean-bottom ambient noise studies that imaged the shearwave velocity profile of tens of kilometers long sedimentary structures (Spica et al., 2020; Cheng et al., 2021; Tonegawa et al., 2021; Williams et al., 2021), here we apply ambient noise tomography at the scale of few hundreds-of-meters to resolve the complex velocity structure beneath a short $2.5 \mathrm{~km}$-long section of the optical fiber buried in a shallow sedimentary basin offshore Methoni (Greece). This basin displays several rapid lateral variations of the resonance frequency and seismic velocities over a very short distance. Thus, resolving this complex velocity structure is a challenging task that requires the fine spatial sampling of the wavefield achieved by DAS.

To reliably image geological structures, even in the presence of strong lateral variations, we augment the velocity model with power spectral densities (PSD) and autocorrelations (AC) that are useful in understanding local resonance and wave propagation. The PSD is a valuable tool for structural imaging, earthquake hazard mitigation, and engineering purposes as it reveals the basin's response with extremely high resolution and provides a detailed view of frequency-dependent site amplification. Such high-resolution PSDs have been previously generated with waveform simulations in enclosed basins (e.g., Bielak et al., 1999; Sanchez-Sesma et al., 1993; Semblat et al., 2005) but to the best of our knowledge, this study presents the first real-world observations. Similar to the use of CC to obtain the Green's function between different measurement locations, AC represents the 1D Green's function with co-located source and receiver (Claerbout, 1968). Such AC signals have been previously used to map strong impedance contrasts (e.g., Romero \& Schimmel, 2018; Taylor et al., 2016), and highlight underwater sedimentary structures and identify fault zones using underwater DAS (Spica et al., 2020; Cheng et al., 2021).

Finally, to examine the inferred shear-wave velocity model, we conducted numerical wave propagation simulations and found good agreement between observations and simulations. The insights obtained from the simulations highlight the strength of underwater DAS in probing wave propagation processes in sedimentary basins, such as scattering, multi-dimensional resonance, and basin edge effects, which are important for the quantification of site effects for seismic hazard assessment.

\section{Geological Setting and Fiber Optic Layout and Measurements}

Methoni basin is located in the very southwest part of Greece and corresponds, for the most part, to the eponymous bay, connected to the Ionian sea. This shallow sedimentary basin is bounded by Methoni village and the mainland in the north and east, Sapientza island in the south, and a natural partially underwater barrier to the west (Figure 1b). The geological settings are described in detail in Text S1. 
(a)

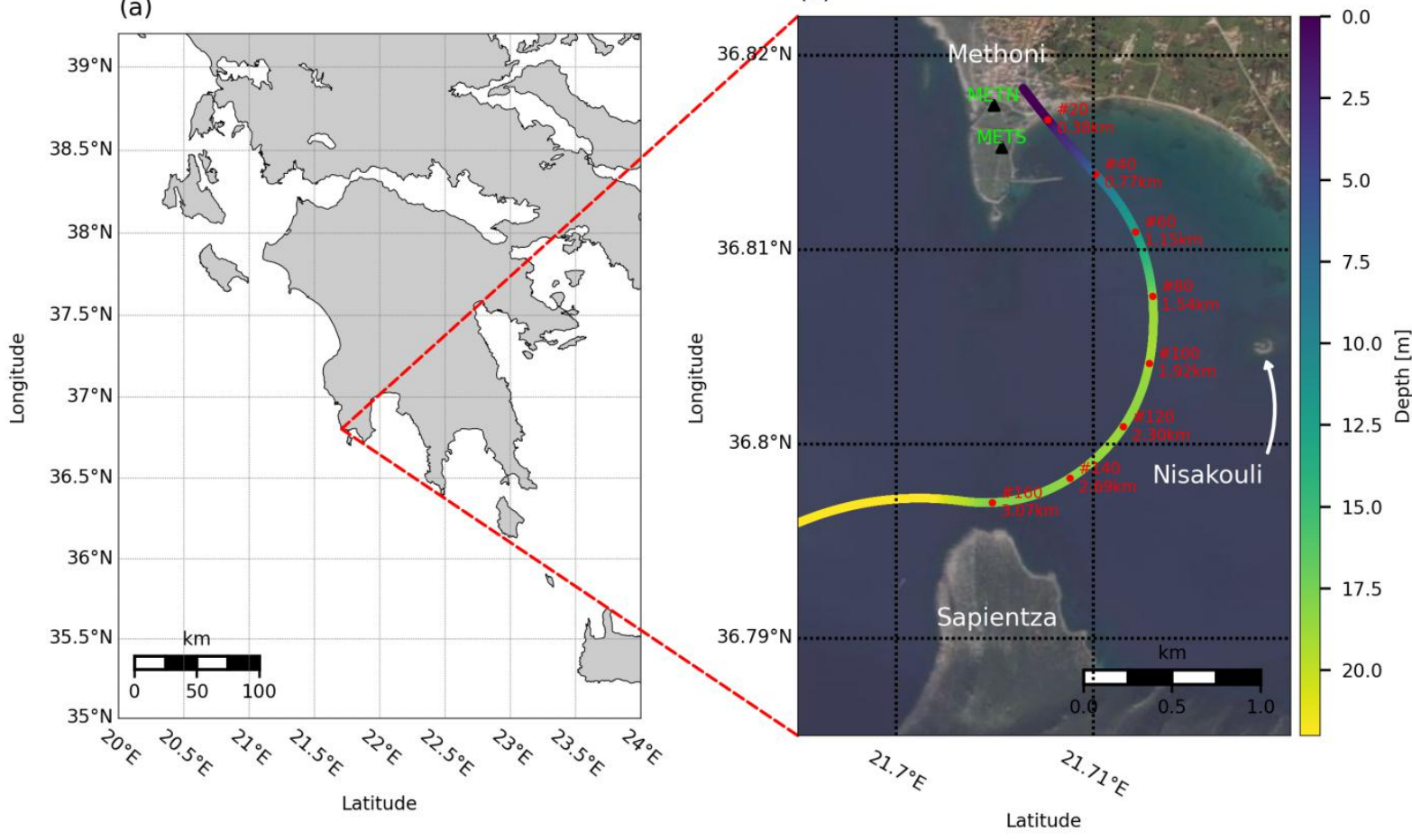

Figure 1. Map of the study area. (a) South Greece, study area is marked by red lines. (b) Aerial map of Methoni basin, the fiber location is color coded by water depth and channel numbers and distances along the fiber are indicated. On-land seismometers are marked by black rectangles.

To image the structure of the Methoni basin, we used underwater DAS ambient noise measurements recorded between April 19th and 25th 2019 by the first $2.5 \mathrm{~km}$ of a standard telecommunication optical fiber cable, buried at $\sim 1 \mathrm{~m}$ beneath the sediments. As the cable was buried in shallow waters, its route is relatively well-constrained. The measurement setup is detailed in text $\mathrm{S} 2$.

When entering the sea, the cable is deployed over Alluvium deposits (Fytrolakis, 1980) (Figure 1b), and it is buried under soft underwater sediments until it reaches the Limestone formations at the western edge of the basin. The extension of the Flysch formation, which covers the eastern edge of the basin and Nisakouli island (Figure 1b) (Fytrolakis, 1980), onto the seabed is unknown, and it may exist beneath limited cable sections. It is also expected that the Limestone formations extend beneath the Alluvium and Flysch, and result in a sharp velocity contrast.

\section{Results}

\subsection{Shear-Wave Velocity Model}

\subsubsection{Extracting Scholte-Wave Dispersion curves}

DAS recordings in Methoni bay are dominated by surface gravity waves and ambient noise Scholte waves. The latter is used here to image the structure beneath Methoni bay. These Scholte-waves are observed here at frequencies between 1 and $5 \mathrm{~Hz}$ (e.g. 
(a)

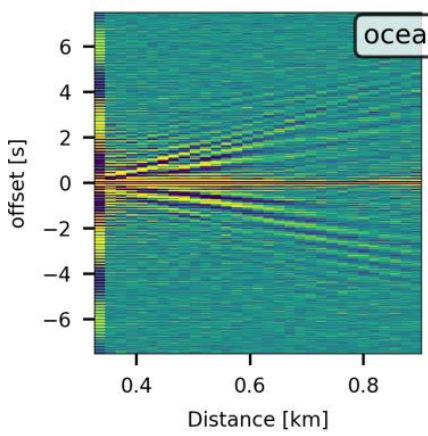

(e)

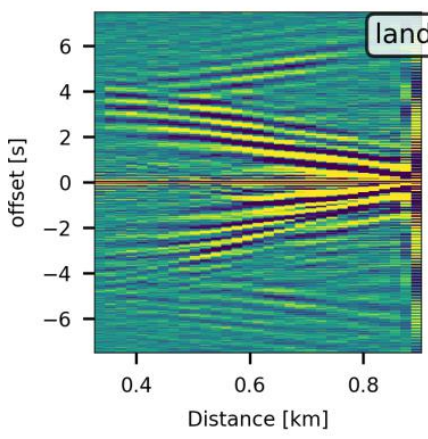

(b)

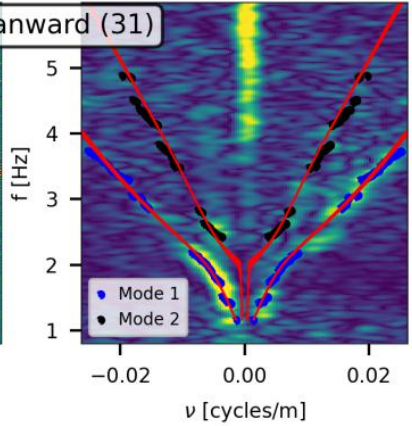

(f)

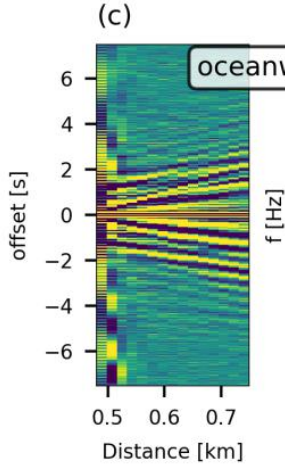

(g) (d)

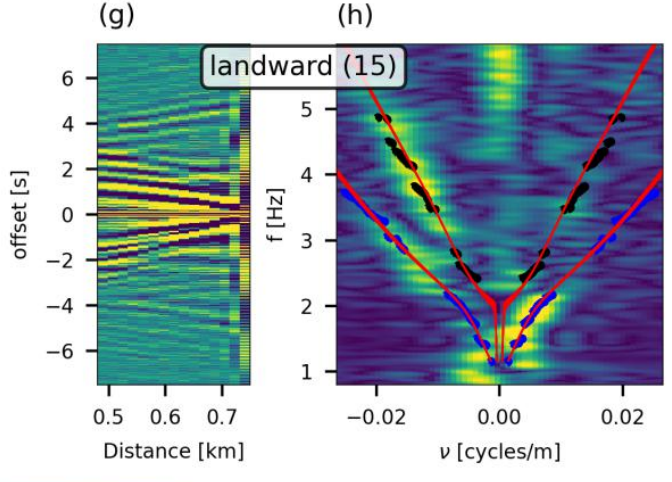

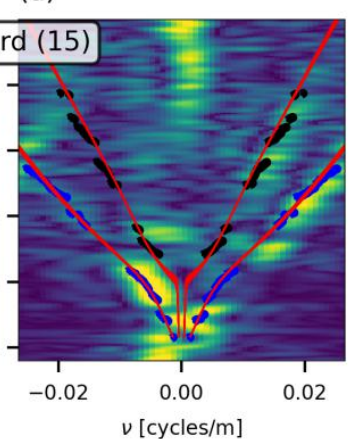

(h)
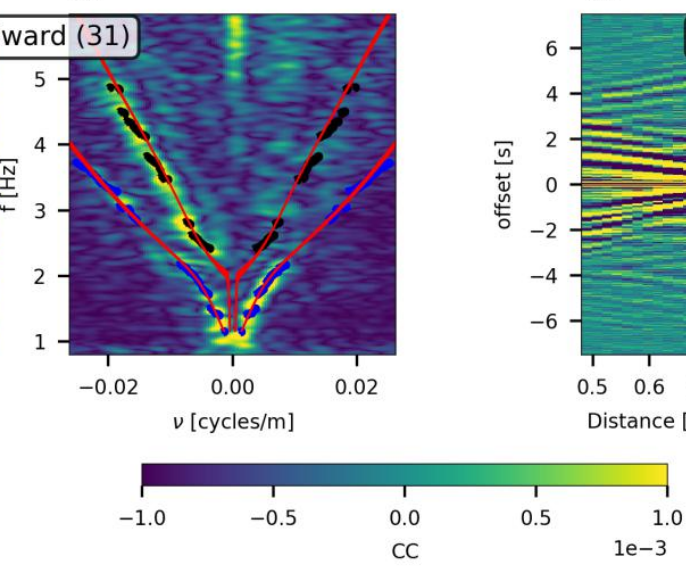

Figure 2. CC gathers and corresponding FK transforms around channel 32 calculated: oceanward using (a-b) 31 and (c-d) 15 channel fiber segments, and landward using (e-f) 31 and (gh) 15 channel fiber segments. FK transforms in panels (b, $d, f$ and $h$ ) are calculated for the CC gathers in panels (a, c, e and g) following zero-padded. The picked fundamental and first higher modes are indicated by blue and black circles, respectively (panels b, $\mathrm{d}, \mathrm{f}$ and $\mathrm{h}$ ). Theoretical dispersion curves associated with the best fitting shear-wave profiles are plotted in red curves for each of the ten different inversions (panels b, $d, f$ and $h$ ). These represent the velocity model beneath channel 32 along the fiber. The colorbar corresponds to panels (a, c, e and g).

Sladen et al., 2019), and are locally amplified and modulated by the sedimentary structure beneath the fiber (Lior et al., 2021a).

To estimate the velocity structure, we retrieve empirical Green's functions by calculating $\mathrm{CC}$ on short cable sections and pick Scholte-wave phase-velocity dispersion curves in the frequency-wavenumber $(\mathrm{FK})$ domain. To resolve small-scale lateral structure variations while maintaining reasonable wavenumber resolution, short cable segments of 31 and 15 equally spaced channels (595.2 $\mathrm{m}$ and $288 \mathrm{~m}$, respectively) were used to compute CC both in oceanward and landward directions. Green's function retrieval and dispersion curve picking are detailed in text S3. For many locations along the fiber, each of the four CC gathers and FK transforms reveals slightly different dispersion characteristics. Such differences are shown in Figure 2. The shoreline is located at channel $19(\sim 365 \mathrm{~m})$, so part of the longer (31 channels) segment is located on-land. Landward CC gathers show reflections from the edge of the basin (Figure 2e and $2 \mathrm{~g}$ from $3 \mathrm{~s}$ ), suggesting a sharp impedance contrast. Similar behavior is observed at the other edge of the basin (not shown). Furthermore, the energy of the longer oceanward segment (Figure 2a and 2b) is lower 
compared to the other $\mathrm{CC}$ gathers since the virtual source is located on-land. In addition, for landward FK (Figure $2 \mathrm{f}$ and $2 \mathrm{~h}$ ), the first higher mode is significantly more visible compared with oceanward FK (Figure $2 \mathrm{~b}$ and $2 \mathrm{~d}$ ). Thus, considering all four gathers when picking dispersion curves provides a more complete image of Scholte-wave propagation, as indicated by the blue and black circles in Figure 2 (panels b, d, f and h), which correspond to the picked fundamental and first higher modes, respectively.

\subsubsection{Retrieving a 2D Velocity Model from Scholte-wave dispersion curves}

The $2 \mathrm{D}$ shear-wave velocity profile beneath the fiber is resolved in two stages. First, we invert for a one-dimensional (1D) profile beneath each short segment of the fiber. Then, we select one location where a reliable profile was obtained and invert for its neighboring profiles, allowing for small changes $(10 \%)$ with respect to adjacent, previously estimated profiles. The second step is performed recursively to obtain a smoothed $2 \mathrm{D}$ velocity model. The inversion algorithm is based on the Neighbourhood Algorithm (NA) developed by Sambridge (1999), and the implementation introduced by Mordret et al. (2014), as further described in Text S4.

Each 1D shear-wave velocity model is composed of a water layer, three solid layers and a bottom half-space; Overall we invert for seven parameters: three layer thicknesses and four velocities. We found that this configuration provides sufficient spatial resolution in depth while preventing model overfitting. As the starting point for the $2 \mathrm{D}$ model, we chose channel $32(615 \mathrm{~m})$ along the fiber, previously displayed in Figures 2, where the fundamental and first higher modes are resolved at a broad frequency range, and nearly identical velocity profiles were obtained for ten NA inversions initialized with different starting models (red curves in panels b, $d, f$ and $h$ of Figure 2 and Figure $S 1$ ). Since the velocity of the bottom half-space is poorly constrained $(1617 \pm 206 \mathrm{~m} / \mathrm{s})$, we turn to the on-land seismic stations (Figure 1b) located on the limestone formations, assuming that they are located on the same geological formation found at the bottom of the basin. This assumption is reasonable given the geological setting described in Section 2. CC calculations on ambient noise recorded by the two on-land stations (Figure 1b) are described in Text S4. This analysis suggests a shear-wave velocity of $1811 \pm 73 \mathrm{~m} / \mathrm{s}$, consistent with that expected for fractured limestone.

To obtain a $2 \mathrm{D}$ velocity profile, the inversion was recursively applied along both fiber directions (oceanward and landward), starting at channel 32, with fixed bottom halfspace velocity of $1.8 \mathrm{~km} / \mathrm{s}$, as estimated from on-land CC. The smoothed 2D velocity model is plotted in Figure 3a. The model displays several prominent features: 1) a steep velocity contrast between the bedrock $(\mathrm{Vs}=1800 \mathrm{~m} / \mathrm{s})$ and the overlying layer $(\mathrm{Vs}=468 \pm 90 \mathrm{~m} / \mathrm{s})$, 2) two deeper sediment regions around channels 50 and 80, and 3) sedimentary layers are generally thinner towards the basin edges.

\subsection{Power Spectral Density and Auto-Correlation}

To further investigate the basin geometry, strain-rate PSDs and AC were calculated as detailed in Text S5. The PSD $\frac{1}{T}|Y(f)|^{2}$ is the Fourier transform of the AC function $\frac{1}{T} y(t) * y(t)$. The latter preserves the phase which conveys more information on the characteristics of wave propagation, while the former is useful in identifying frequency- 
(a)

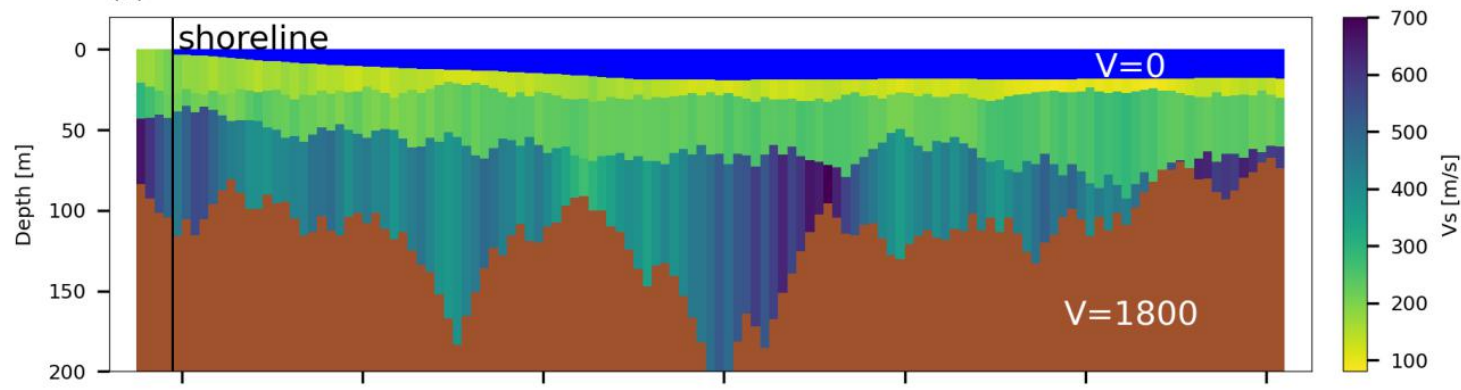

(b)

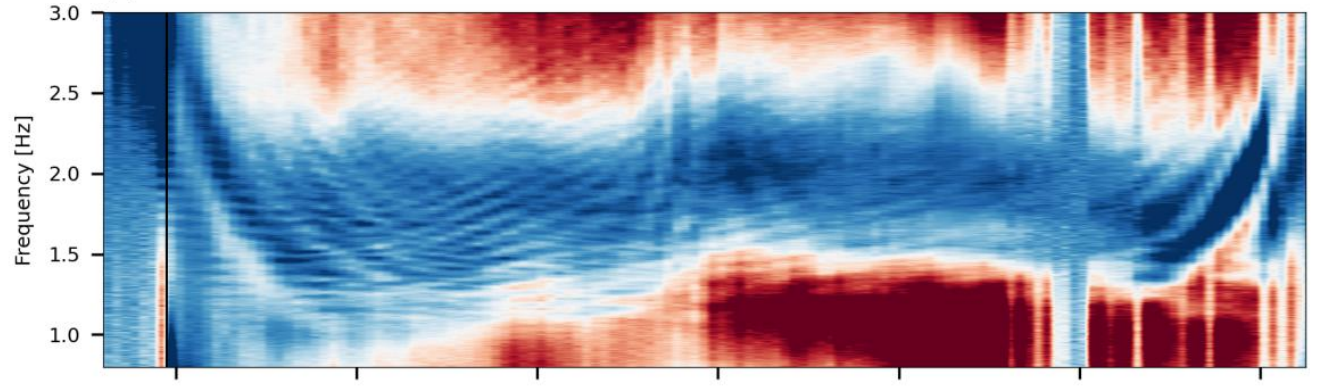

(c)

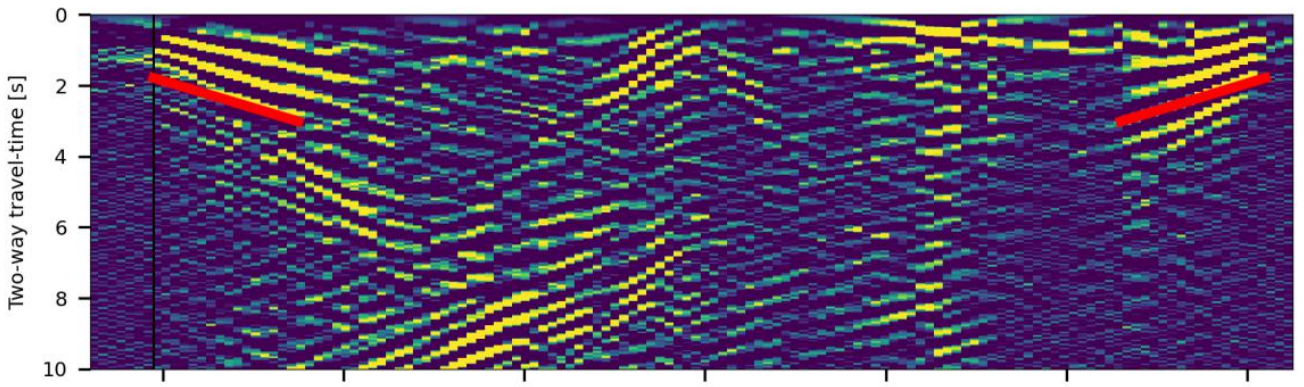

(d)

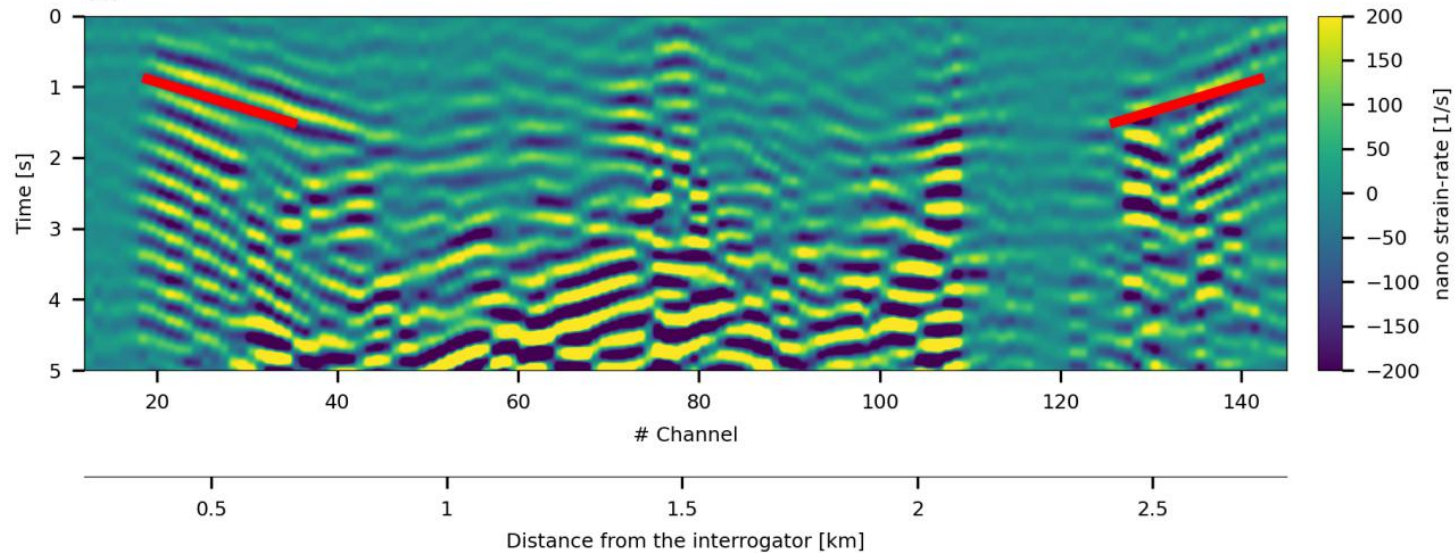

Figure 3. (a) 2D shear wave velocity profile along the fiber, (b) Amplitude corrected PSD, (c) AC following FK filter to remove velocities lower than $800 \mathrm{~m} / \mathrm{s}$ (d) 5 seconds following the direct Swave of a magnitude 2 earthquake recorded at a distance of $37 \mathrm{~km}$, bandpass filtered between 1 and $3 \mathrm{~Hz}$. In (a), the velocity of the bottom half space and water layer are fixed at $1.8 \mathrm{~km} / \mathrm{s}$ and 0 , respectively. Red lines in (c) and (d) indicate velocities of $500 \mathrm{~m} / \mathrm{s}$. The shoreline is indicated by black vertical lines in (a)-(c).

dependent resonance and basin amplification effects (e.g., Bielak et al 1999; Sanchez-Sesma 
et al., 1993; Semblat et al. 2005).

\subsection{Earthquake Observations}

To support the observed AC (Figure 3c), we investigate wave propagation characteristics of earthquakes recorded by the fiber. Since earthquake recordings are a convolution of the source time-function and the Green's function between source and receiver positions, near-vertical seismic arrivals are closely related to the 1D Green's functions displayed in the AC image (Figure 3c). We examined four different local earthquakes that occurred at different locations and source-fiber azimuths (Lior et al., 2021a) for which near-vertical direct body wave arrivals are expected. Apart from SNR variations, wave propagation is extremely similar for the different earthquakes, suggesting that local effects dominate these recordings. The first five seconds following the direct Swave arrival of a magnitude 2 at a hypocentral distance of $37 \mathrm{~km}$ are plotted in Figure $3 \mathrm{~d}$. These signals significantly resemble the $\mathrm{AC}$ in Figure $3 \mathrm{c}$.

\subsection{Numerical simulations}

To support the obtained velocity model (Figure 3a), we conducted 2D numerical wave propagation simulations in a simple, smooth basin model, as previously done by Lior et al. (2021b). These simulations cannot capture the full propagation characteristics expected from 3D wave propagation in such a complex real medium, recorded by a curved sensor array (Figure 1b); They were conducted to qualitatively recreate the general features resolved by the velocity model in Figure 3 and understand their relation to wave propagation. In particular, the patterns of seismic response of a basin, observed here via PSD and AC analysis, results from both lateral and vertical resonances (e.g., Bielak et al 1999), which are partially captured by a 2D simulation.

Two velocity models are tested (Figures S4a and $4 \mathrm{a}$ ), which are smoothed versions of that shown in Figure 3a. The two models differ in the manner in which the depth of the bottom layer varies surrounding channel 80. Since the obtained 2D model (Figure 3a) is affected by the inversion approach, which allows for small model variations between adjacent 1D profiles (Section 3.1.2), the estimated layer interface may in fact be steeper. Thus, in Figure 4a we model a steeper increase in depth with respect to that in Figure S4a. In these modified models, each layer has uniform seismic velocities, set as the average of the layer velocities in the original model (Figure 3a), and smoothed layer interfaces. The velocity model in Figure 3a does not show obvious basin edges at the two ends of the model, most likely due to the rapid lateral variations and smoothing constraints of the 2D inversion. However, observed PSD and AC show clear basin edge patterns identified as increasing frequencies (Figure 3b) and scattered waves (Figure 3c), respectively. To qualitatively reproduce the observed basin edge patterns, the models in Figures S4a and 4a were manually closed on both lateral ends to generate strong impedance contrasts at the basin's edges that enable lateral resonance in the basin. The simulation set-up is further described in Text S6.

PSD (Figures S4b and 4b) and AC (Figures S4c and 4c) are obtained as described in Text S5. To highlight the same frequencies as in the observed PSD (Figure 3b), the simulated PSDs were divided by the spectrum of the Ricker wavelet used as source time function in the simulations (see Text S6) and multiplied by the average (along the spatial 


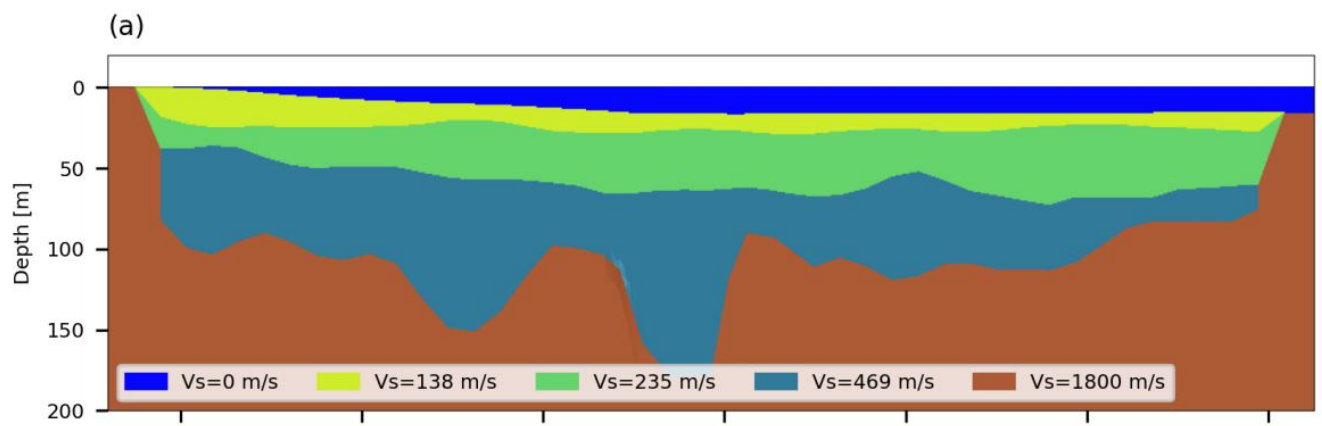

(b)

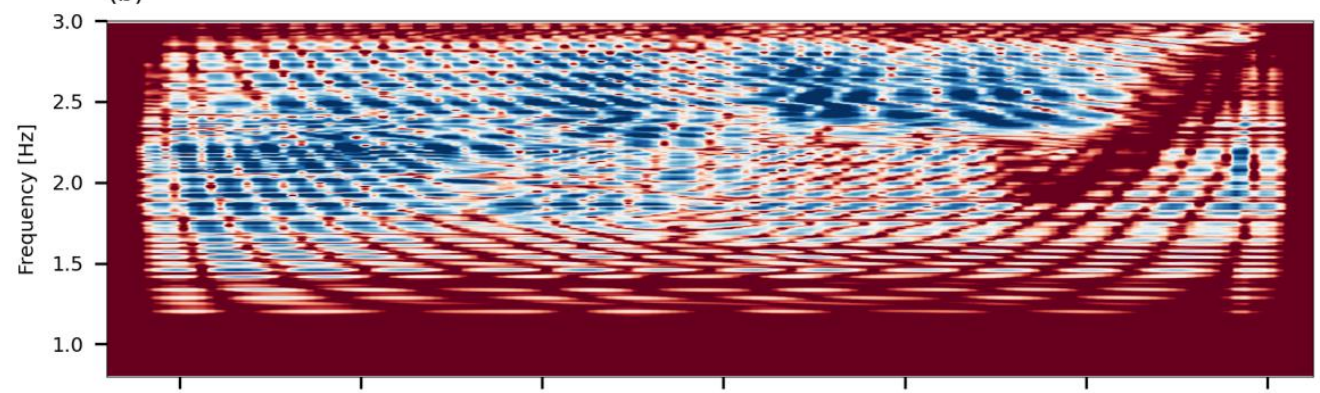

(c)

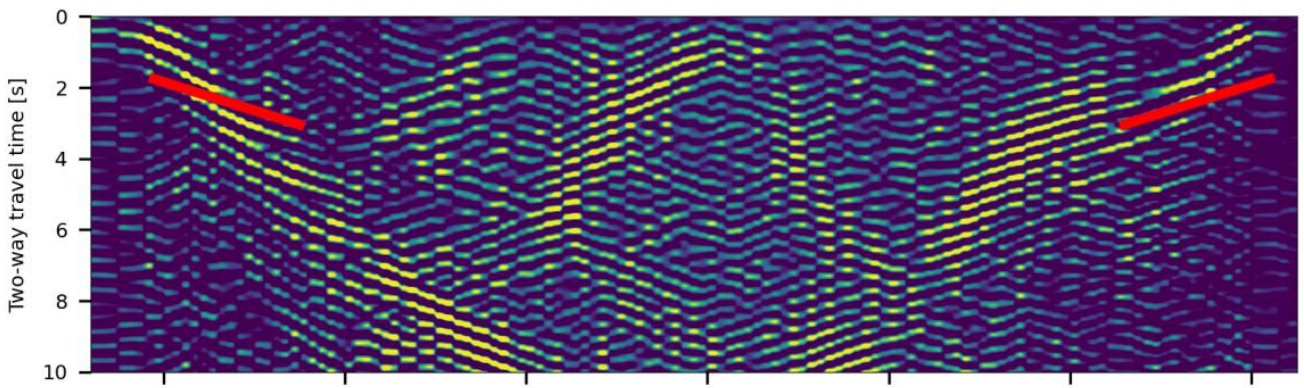

(d)

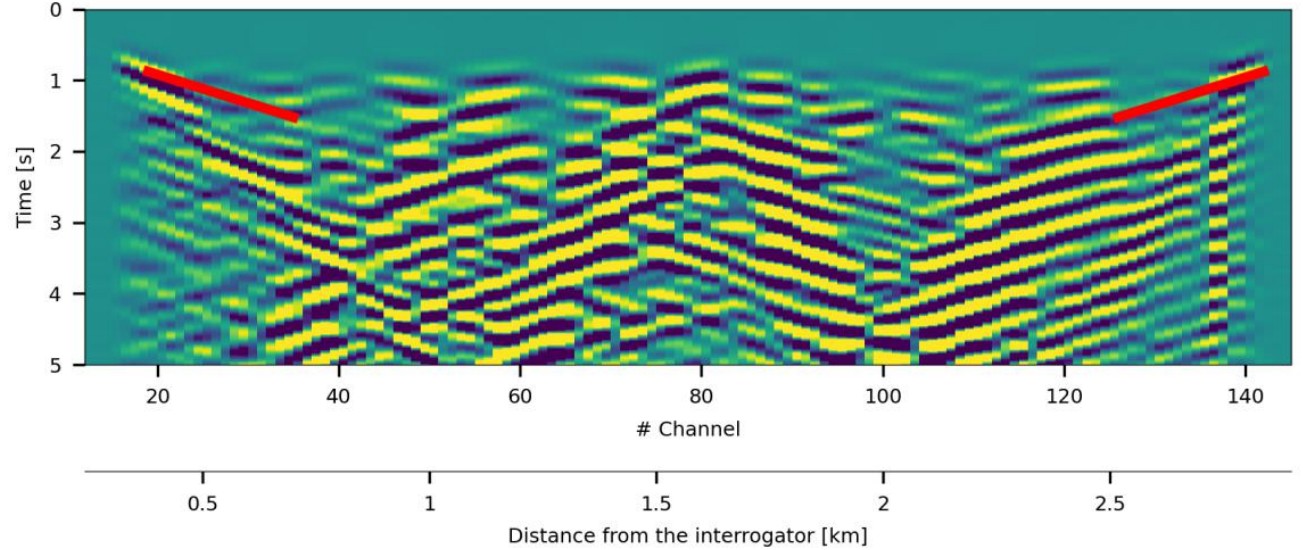

Figure 4. Simulation results for a steep increase of bedrock depth around channel 80. (a) Smoothed 2D shear-wave velocity profile. Layer velocities are indicated in the legend. (b) PSD and (c) AC calculations. PSD are convoluted with the average observed PSD (see text). An FK filter is applied to the AC in (c) to remove velocities lower than $800 \mathrm{~m} / \mathrm{s}$. (d) The first 5 seconds of the simulated waveforms. Red lines in (c) and (d) indicate velocities of $500 \mathrm{~m} / \mathrm{s}$.

axis) observed (Figure 3b) PSDs. For comparison with the earthquake recording in Figure $3 \mathrm{~d}$, the first five seconds of the simulation are shown in Figures S4d and $4 \mathrm{~d}$. 


\section{Discussion}

Each individually-inverted 1D profile represents the velocity beneath its associated $\mathrm{CC}$ gather, assuming negligible lateral variations. Thus, each 1D profile should be treated with caution, as it may be biased by lateral variations within the CC fiber segment (at least 15 channels, i.e., $288 \mathrm{~m}$ ). For fiber segments with strong lateral variations, the information carried by the PSD and AC is crucial, as discussed further.

Several features in the estimated velocity model (Figure $3 a$ ) have clear signatures in the observed PSD (Figure 3b), AC (Figure 3c) and earthquake recording (Figure 3d). Sedimentary layers generally get thinner towards the edges of the basin (panel a), causing reflections seen in both the AC (panels c) and earthquake record (panel d). These reflected waves propagate at velocities of 400 to $600 \mathrm{~m} / \mathrm{s}$, as indicated by the reference $500 \mathrm{~m} / \mathrm{s}$ red curves. Basin edge effects, a result of interference between vertical and lateral resonances, also appear in the PSD (panel b) as a frequency increase towards the basin's edges, as predicted by wave-propagation simulation studies (e.g., Papageorgiou \& Kim, 1991; Sanchez-Sesma et al., 1993). The deeper sediment region around channel 80 (panel a) is associated with a striking triangular shape in the $\mathrm{AC}$ and earthquake recording, as well as a local PSD frequency increase, suggesting scattered waves. Another clear feature in the AC and earthquake signal are late ( 7 to 10 seconds) landward propagating waves, seen from channel 40 to 80 (panel c). These cannot be correlated with any feature in the velocity model (panel a), and may be a result of a deeper velocity structure.

At the basin's edges, significant lateral variations and a sharp impedance contrast result in horizontally reflected waves (e.g., CC gathers in Figure 2) as well as abrupt disruption of seismic signals at channels 19 (shoreline) and 145 (Figure 3b-3d). The latter may also be a result of unfavorable cable-ground coupling. This impedance contrast is not properly resolved in the 2D profile (Figure 3a). To address this issue and improve the physical reliability of the simulations, the models were manually closed ("pinned-up") on both sides (Figures S4a and 4a), and reliably reproduce the observed reflections (Figure S4c-d and 4c-d). It should be noted that simulated waves (Figure S4d and 4d) reflected from the left (on-land) edge of the basin exhibit dispersive characteristics, not observed in the earthquake recording (Figure 3d).

The waveform simulations in Figures S4 and 4 are found to be in good agreement with observations (Figure 3), supporting the estimated 2D velocity model. Specifically, the simulations that exhibit a steeper depth change for the bottom layer around channel 80 (Figure 4) better reproduced the observations. This agreement is observed for waves reflected from the basin edges, where observations and simulations show similar velocities (Figure $3 \mathrm{c}$ and $4 \mathrm{c}$, and $3 \mathrm{~d}$ and $4 \mathrm{~d}$ ). The increasing frequencies at the basin edges are also well reproduced in the PSD. The AC and PSD features seen around channel 80 (Figure 3b$3 c$ ) are qualitatively reproduced by the simulations (Figure $4 b-4 c$ ), a result of complex wave propagation associated with the sharp increase in the depth of the bottom layer. As expected, waves seen at 7 to 10 seconds in Figure 3c (channels 40 to 80 ) are not reproduced in Figure 4c, further suggesting that these are related to a deeper velocity structure.

The PSD and AC features observed around channel 80 (Figure 3b-3c), are caused by lateral wave propagation effects that may be associated with several different structural phenomena. This structure may be an underwater canyon, filled with low-velocity sediments, that generates reflected waves from its edges. Another option is hinted by the 
proximity of channel 80 to Nisakouli island (Figure 1), where a Flysch formation is outcropping on the island (Fytrolakis, 1980). The Flysch may extend underwater beneath the fiber and appear as a low-velocity outcrop overlaying the limestone formation (bottom layer). The relation between the different formations may play a role in generating $3 \mathrm{D}$ wave propagation complexities associated with the observations. A third possibility is that this region corresponds to a localized fault zone, characterized by low velocity fractured rocks. Such a structure would display trapped high-frequency waves and generate an indicative triangular wave propagation pattern (e.g., Lindsey et al., 2019; ; Spica et al., 2020). Also, an increase in the PSD frequency content, as seen here (Figure 3b), can originate from wave propagation effects at the boundary between two sub-basins (e.g., Bielak et al 1999), but may equivalently be generated if a curved fiber approaches any edge of the basin. Such boundaries may appear in the velocity model (Figures 3a, S4a and $4 \mathrm{a}$ ) at channels $\sim 60$ and $\sim 90$ for the left and right sub-basins, respectively, yet these are too subtle and cannot reproduce the AC and PSD observations (Figure 3b-3c) as demonstrated by the simulations in Figure S4. With a significant lack of ground truth, we cannot determine which of these hypotheses is the valid one. Further simulations and broader scale imagery should be conducted to accurately resolve this structure and understand local wave propagation.

\section{Conclusions}

We demonstrated the ability to image the shear-wave velocity model beneath a short underwater optical fiber using continuous ambient noise recordings. AC and PSD provide a detailed view of wave propagation effects, and basin resonance and amplification patterns, respectively. To the best of our knowledge, this is the first time that such high-resolution AC and PSD were obtained using real-world observations. A smoothed 2D velocity model was obtained by analyzing the dispersion of Scholte-waves using short fiber segments. This model was modified following the insights gained from the PSD and AC analysis, and subsequent waveform simulations revealed a good agreement with observations. However, additional knowledge and constraints on local underwater geology are required to reliably interpret the obtained model.

The imagery approach used here is the first step towards a method that combines surface wave dispersion as well as AC and PSD analysis using DAS fiber optic data. Such a method will account for both lateral and vertical resonance to reliably and objectively image complex structures in $2 \mathrm{D}$ and allow for greater sensitivity to strong lateral variations. For a more complete 3D model, additional broadband seismometers and/or augmenting optical fibers should be used. Waveform simulations proved to be an excellent tool to validate the inferred model, and should be used and expanded to 3D as needed.

\section{Acknowledgments}

This work and IL were supported by the SEAFOOD project, funded in part by grant ANR-17-CE04-0007 of the French Agence Nationale de la Recherche. Part of the project was also supported by Universite Cote d'Azur IDEX program UCAJEDI ANR-15IDEX-0001 and the Doeblin Federation (FR2800 CNRS). We thank Stavroula Tsagkli, Katerina Tzamarioudaki and Christos Markou from NCSR Demokritos, the Greek Institute of Nuclear and Particle Physics, who maintain the NESTOR cable infrastructure 
and facilitated the acquisition campaign. This infrastructure is part of the European Multidisciplinary Seafloor and water column Observatory (EMSO).

\section{Data Availability Statement}

Simulated and observed DAS earthquakes are available on https://osf.io/98cnk/ and https://osf.io/4bjph/, respectively.

\section{References}

Ajo-Franklin, J. B., Dou, S., Lindsey, N. J., Monga, I., Tracy, C., Robertson, M., Rodriguez Tribaldos, V., Ulrich, C., Freifeld, B., Daley, T., \& Li, X. (2019). Distributed acoustic sensing using dark fiber for near-surface characterization and broadband seismic event detection. Scientific Reports, 91). doi: 10.1038/s41598-018-36675-8

Anassontzis, E., \& Koske, P. (2003). Deep-sea station connected by cable to the shore. Sea Technology, 44, 10-14.

Bensen, G. D., Ritzwoller, M. H., Barmin, M. P., Levshin, A. L., Lin, F., Moschetti, M. P., Shapiro, N. M., \& Yang, Y. (2007). Processing seismic ambient noise data to obtain reliable broad-band surface wave dispersion measurements. Geophysical Journal International, 1693), 1239-1260. doi: 10.1111/j.1365-246X.2007.03374.X

Bielak, J., Xu, J., \& Ghattas, O. (1999). Earthquake ground motion and structural response in alluvial valleys. Journal of Geotechnical and Geoenvironmental Engineering, 125(5), 413-423. doi: 10.1061/(ASCE)1090-0241(1999)125:5(413)

Biot, M. A. (1952). The interaction of Rayleigh and Stoneley waves in the ocean bottom. Bulletin of the Seismological Society of America, 42(1), 81-93. doi: 10.1785/BSSA0420010081

Cheng, F., Chi, B., Lindsey, N. J., Dawe, T. C., \& Ajo-Franklin, J. B. (2021). Utilizing distributed acoustic sensing and ocean bottom fiber optic cables for submarine structural characterization. Scientific Reports, 11(1). doi: 10.1038/s41598-02184845-y

Claerbout, J. F. (1968). Synthesis of a layered medium from its acoustic transmission response. Geophysics, 33(2), 264-269. doi: 10.1190/1.1439927

Dou, S., Lindsey, N., Wagner, A. M., Daley, T. M., Freifeld, B., Robertson, M., Peterson, J., Ulrich, C., Martin, E. R., \& Ajo-Franklin, J. B. (2017). Distributed acoustic sensing for seismic monitoring of the near surface: a traffic-noise interferometry case study. Scientific Reports, 入1). doi: 10.1038/s41598-017-11986-4 
Foti, S., Hollender, F., Garofalo, F., Albarello, D., Asten, M., Bard, P.-Y., Comina, C., Cornou, C., Cox, B., Di Giulio, G., Forbriger, T., Hayashi, K., Lunedei, E., Martin, A., Mercerat, D., Ohrnberger, M., Poggi, V., Renalier, F., Sicilia, D., \& Socco, V. (2018). Guidelines for the good practice of surface wave analysis: a product of the InterPACIFIC project. Bulletin of Earthquake Engineering, 16(6), 2367-2420. doi: 10.1007/s10518-017-0206-7

Fytrolakis N. (1980). Geological Map of Greece, scale 1:50.000, KORONI-PYLOS-SKHIZA sheet, IGME, Athens.

Guerin, G., Rivet, D., Deschamps, A., Larroque, C., Mordret, A., Dessa, J.-X., \& Martin, X. (2020). High resolution ambient noise tomography of the Southwestern Alps and the Ligurian margin. Geophysical Journal International, 220(2), 806-820. doi: 10.1093/gii/ggz477

Hable, S., Sigloch, K., Stutzmann, E., Kiselev, S., \& Barruol, G. (2019). Tomography of crust and lithosphere in the western Indian Ocean from noise cross-correlations of land and ocean bottom seismometers. Geophysical Journal International, 219(2), 924-944. doi: $10.1093 / \mathrm{gji} / \mathrm{ggz} 333$

Herrmann, R.B. \& Ammon, C.J. (2004), Surface waves, receiver functions and crustal structure. Computer Programs in Seismology.

Komatitsch, D., Vilotte, J.-P., Cristini, P., Labarta, J., Le Goff, N., Le Loher, P., Liu, Q., Martin, R., Matzen, R., Morency, C., Peter, D., Tape, C., Tromp, J., and Xie, Z. (2012), SPECFEM2D v7.0.0 software, Computational Infrastructure for Geodynamics.

Kraft, J. C., \& Aschenbrenner, S. E. (1977). Paleogeographic reconstructions in the methoni embayment in greece. Journal of Field Archaeology, 4(1), 19-44. doi: $\underline{10.1179 / 009346977791490357}$

Lin, F.-C., Moschetti, M. P., \& Ritzwoller, M. H. (2008). Surface wave tomography of the western United States from ambient seismic noise: Rayleigh and Love wave phase velocity maps. Geophysical Journal International, 173(1), 281-298. doi: 10.1111/j.1365-246X.2008.03720.x

Lindsey, N. J., Dawe, T. C., \& Ajo-Franklin, J. B. (2019). Illuminating seafloor faults and ocean dynamics with dark fiber distributed acoustic sensing. Science, 366(6469), 1103-1107. doi: $10.1126 /$ science.aay5881 
Lior, I., Sladen, A., Rivet, D., Ampuero, J., Hello, Y., Becerril, C., Martins, H. F., Lamare, P., Jestin, C., Tsagkli, S., \& Markou, C. (2021a). On the detection capabilities of underwater distributed acoustic sensing. Journal of Geophysical Research: Solid Earth, 126(3). doi: 10.1029/2020JB020925

Lior, I., Sladen, A., Mercerat, D., Ampuero, J.-P., Rivet, D., \& Sambolian, S. (2021 b). Strain to ground motion conversion of distributed acoustic sensing data for earthquake magnitude and stress drop determination. Solid Earth, 12(6). 14211442. doi: $10.5194 / \mathrm{se}-12-1421-2021$

McNamara, D. E., \& Buland, R. P. (2004). Ambient noise levels in the continental united states. Bulletin of the Seismological Society of America, 94(4), 1517-1527. doi: $\underline{10.1785 / 012003001}$

Mordret, A., Landès, M., Shapiro, N. M., Singh, S. C., \& Roux, P. (2014). Ambient noise surface wave tomography to determine the shallow shear velocity structure at Valhall: depth inversion with a Neighbourhood Algorithm. Geophysical Journal International, 198(3), 1514-1525. doi: 10.1093/gji/ggu217

Nishida, K., Montagner, J.-P., \& Kawakatsu, H. (2009). Global surface wave tomography using seismic hum. Science, 326(5949), 112-112. doi: 10.1126/science.1176389

P. Kruiver, P., Deák, A., \& El Allouche, N. (2010). Extraction of geotechnical properties from Scholte waves in underwater environments. First International Conference on Frontiers in Shallow Subsurface Technology, Delft, Netherlands,. doi: 10.3997/2214-4609-pdb.150.A05

Papageorgiou, A. S., \& Kim, J. (1991). Study of the propagation and amplification of seismic waves in Caracas Valley with reference to the 29 July 1967 earthquake: SH waves. Bulletin of the Seismological Society of America, 81(6), 2214-2233.

Park, C. B., Miller, R. D., \& Xia, J. (1999). Multichannel analysis of surface waves. Geophysics, 64(3), 800-808. doi: 10.1190/1.1444590

Romero, P., \& Schimmel, M. (2018). Mapping the basement of the Ebro basin in Spain with seismic ambient noise autocorrelations. Journal of Geophysical Research: Solid Earth, 123(6), 5052-5067. doi: 10.1029/2018JB015498 
Sambridge, M. (1999). Geophysical inversion with a neighbourhood algorithm-I. Searching a parameter space. Geophysical Journal International, 138(2), 479-494. doi: 10.1046/j.1365-246X.1999.00876.X

Sánchez-Sesma, F. J., Ramos-Martínez, J., \& Campillo, M. (1993). An indirect boundary element method applied to simulate the seismic response of alluvial valleys for incident P, S and Rayleigh waves. Earthquake Engineering \& Structural Dynamics, 22(4), 279-295. doi: 10.1002/eqe.4290220402

Schimmel, M. (1999). Phase cross-correlations: Design, comparisons, and applications. Bulletin of the Seismological Society of America, 89(5), 1366-1378. doi: 10.1785/BSSA0890051366

Semblat, J. F., Kham, M., Parara, E., Bard, P. Y., Pitilakis, K., Makra, K., \& Raptakis, D. (2005). Seismic wave amplification: Basin geometry vs soil layering. Soil Dynamics and Earthquake Engineering, 25(7-10), 529-538. doi:

10.1016/j.soildyn.2004.11.003

Shapiro, N. M., \& Campillo, M. (2004). Emergence of broadband Rayleigh waves from correlations of the ambient seismic noise. Geophysical Research Letters, 31(7), L07614. doi: 10.1029/2004GL019491

Sladen, A., Rivet, D., Ampuero, J. P., De Barros, L., Hello, Y., Calbris, G., \& Lamare, P. (2019). Distributed sensing of earthquakes and ocean-solid Earth interactions on seafloor telecom cables. Nature Communications, 10(1), 1-8. doi: 10.1038/s41467019-13793-z

Spica, Z. J., Nishida, K., Akuhara, T., Pétrélis, F., Shinohara, M., \& Yamada, T. (2020). Marine sediment characterized by ocean-bottom fiber-optic seismology. Geophysical Research Letters, 4オ16), e2020GL088360. doi: 10.1029/2020GL088360

Taylor, G., Rost, S., \& Houseman, G. (2016). Crustal imaging across the North Anatolian Fault Zone from the autocorrelation of ambient seismic noise. Geophysical Research Letters, 43(6), 2502-2509. doi: 10.1002/2016GL067715 Tonegawa, T., Araki, E., Matsumoto, H., Kimura, T., Obana, K., Fujie, G., Arai, R., Shiraishi, K., Nakano, M., Nakamura, Y., Yokobiki, T., \& Kodaira, S. (2021). Vp and Vs structure estimations from ambient seafloor noise observed by distributed 
acoustic sensing. Earth and Space Science Open Archive. doi: 10.1002/essoar.10507262.2

Williams, E. F., Fernández-Ruiz, M. R., Magalhaes, R., Vanthillo, R., Zhan, Z., GonzálezHerráez, M., \& Martins, H. F. (2021). Scholte wave inversion and passive source imaging with ocean-bottom DAS. The Leading Edge, 40(8), 576-583. doi: 10.1190/tle40080576.1

Wolf, F. N., Lange, D., Dannowski, A., Thorwart, M., Crawford, W., Wiesenberg, L., Grevemeyer, I., Kopp, H., \& the AlpArray Working Group. (2021). 3D crustal structure of the Ligurian Sea revealed by ambient noise tomography using ocean bottom seismometer data. Solid Earth Discussions. doi: 10.5194/se-2021-55

Yao, H., Gouédard, P., Collins, J. A., McGuire, J. J., \& van der Hilst, R. D. (2011). Structure of young East Pacific Rise lithosphere from ambient noise correlation analysis of fundamental- and higher-mode Scholte-Rayleigh waves. Comptes Rendus Geoscience, 343(8-9), 571-583. doi: 10.1016/j.crte.2011.04.004

Yuan, S., Lellouch, A., Clapp, R. G., \& Biondi, B. (2020). Near-surface characterization using a roadside distributed acoustic sensing array. The Leading Edge, 39(9), 646653. doi: $\underline{10.1190 / \text { tle39090646.1 }}$ 